\title{
Assessment of debris-flow susceptibility at medium-scale in the Barcelonnette Basin, France
}

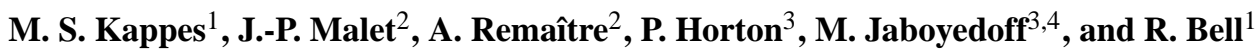 \\ ${ }^{1}$ Institute of Geography and Regional Research, University of Vienna, Vienna, Austria \\ ${ }^{2}$ Institut de Physique du Globe, Université de Strasbourg/EOST, CNRS, Strasbourg, France \\ ${ }^{3}$ Institute of Geomatics and Risk Analysis, IGAR, University of Lausanne, Lausanne, Switzerland \\ ${ }^{4}$ Quanterra, Lausanne, Switzerland
}

Received: 3 February 2010 - Revised: 2 December 2010 - Accepted: 3 December 2010 - Published: 28 February 2011

\begin{abstract}
Debris flows are among the most dangerous processes in mountainous areas due to their rapid rate of movement and long runout zone. Sudden and rather unexpected impacts produce not only damages to buildings and infrastructure but also threaten human lives. Medium- to regional-scale susceptibility analyses allow the identification of the most endangered areas and suggest where further detailed studies have to be carried out. Since data availability for larger regions is mostly the key limiting factor, empirical models with low data requirements are suitable for first overviews. In this study a susceptibility analysis was carried out for the Barcelonnette Basin, situated in the southern French Alps. By means of a methodology based on empirical rules for source identification and the empirical angle of reach concept for the 2-D runout computation, a worst-case scenario was first modelled. In a second step, scenarios for high, medium and low frequency events were developed. A comparison with the footprints of a few mapped events indicates reasonable results but suggests a high dependency on the quality of the digital elevation model. This fact emphasises the need for a careful interpretation of the results while remaining conscious of the inherent assumptions of the model used and quality of the input data.
\end{abstract}

\section{Introduction}

"Debris flows are churning, water-saturated masses of fine sediment, rocks and assorted detritus that originate on mountain slopes and course down-stream channels when they reach valley floors" (Iverson and Denlinger, 2001,

Correspondence to: M. S. Kappes

(melanie.kappes@univie.ac.at) p. 1). They flow "as a single-phase system" and "look like mudslides and landslides except that their velocity and the distances they travel are much larger" (Ancey, 2001, p. 529). According to the origin of the material, debris flows can be classified into slope and gully debris flows (Glade, 2005). Their velocity, the frequently long distances between the source area and the deposition zone and the often apparent insignificance of the source volume, which increases manifold during the runout, make them one of the most dangerous natural hazards occurring in the mountainous environment. They affect not only builtup areas and infrastructure but also threat human lives (Hofmeister et al., 2002). For the management and reduction of risk posed by debris flows, analyses identifying the areas at hazard by debris flows and describing the threat play an important role. According to the purpose of the analyses, the extent of the studied area and the data availability, the analysis scale is chosen (Aleotti and Chowdhury, 1999): regional, medium or local (single slope). Medium-scale analyses, which include according to van Westen et al. (2006) the range between 1:10000 and 1:50000, provide an initial overview of a certain area identifying all potentially unstable areas as far as possible and the down-slope regions probably affected by the flow. Usually they are not used as the basis for final decisions but rather serve, as in the case of Hofmeister and Miller (2003), as initial screens for potential impacts and they offer an indication where further local studies should be carried out. Debris-flow analyses are often split into two steps, (a) the identification of potential sources and (b) the estimation of the runout. For both steps a variety of methods is available:

(a) Heuristically potential sources can be identified as in Benda and Cundy (1990) or Chau and Lo (2004) in the field and on aerial photographs. Statistical

Published by Copernicus Publications on behalf of the European Geosciences Union. 
methods linking a variety of environmental factors contributing to possible instabilities to an inventory of past events are very well-established for the source identification at smaller scales (van Westen et al., 2006). The models are either based on bivariate (Guinau et al., 2007; Blahut et al., 2010; Melelli and Taramelli, 2004) or multivariate statistics (Carrara et al., 2008). Horton et al. (2008) use a methodology for the source identification based on empirical rules. By means of a combination of environmental parameters chosen on the basis of experience, primarily slope angle, upslope area and planar curvature, the debris-flow susceptibility is computed. For physically-based source identification a common option is to couple hydraulic models with the calculation of the safety factor (Delmonaco et al., 2003; Carrara et al., 2008).

(b) While for the source identification statistical models play a dominant role, empirical relationships and formulae are well-established for the runout computation: the Fahrböschung (Heim, 1932) translated to angle of reach (Corominas, 1996) describes the angle between the horizontal and a line connecting the most distal point of deposition with the upper limit of the source area, along the path. This concept enables the estimation of the maximum runout distance if the source area is known. In many cases the angle of reach is expressed as a function of the debris-flow volume (Hürlimann et al., 2008) as in the formulas proposed by Corominas (1996) and Rickenmann (1999). Prochaska et al. (2008) developed the average channel slope model predicting the runout angle, which is the angle between the horizontal and a line between the vertical midpoint of the elevation difference between source area and fan apex and the most distal deposition. Rickenmann (1999) presents a formula predicting the runout distance on the fan as a function of the debris-flow volume. Several other studies associate the volume with the deposition area of the flow as Iverson et al. (1998) or Scheidl and Rickenmann (2010). So far, only a few physically-based runout models have been applied on a medium-scale due to calibration difficulties. Chau and Lo (2004) adjusted a physically-based runout model to one recorded event including friction and erosion and computed the potential runout of several unstable areas on the basis of this adjustment.

While deterministic approaches are very well transferable to basically any site since they consider the physical characteristics of the process, they are characterised by rather high data requirements for the calibration. Statistical models are based on extensive inventories of past events and are, apart from the reliance on good records, only transferable to a very limited extent. This is a consequence of frequent inclusion of indirect parameters as elevation, aspect etc. since these parameters cause very different effects in distinct areas. Empirical models offer an alternative in the case of general low data availability. Empirical models in this study are understood as general rules and relations which are established once on the basis of large datasets and are afterwards usable without the high data needs for calibration deterministic models have. An example is the concept of Fahrböschung according to (Heim, 1932), for more detail refer to the description at the end of the Sect. 3.1. In contrast to statistical models, empirical rules and relations are not based on indirect parameters but on parameters directly linked to physical characteristics. Due to the degree of generalisation from the data on which empirical models were created, they are rather well transferable. If quite similar environmental conditions can be assumed, even calibration parameters can be transferred to a certain extent. A first overview over a relatively unknown area can thus be conducted without many records of past events and detailed environmental information for the model calibration. The simplicity of empirical models is their major advantage and disadvantage, since specific characteristics in single cases cannot be accounted for (Hürlimann et al., 2008). For a debris-flow susceptibility analysis of the Barcelonnette Basin, located in the southern French Alps, an empirical methodology after Horton et al. (2008) was used.

The Barcelonnette Basin is prone to debris-flows. One of the recent damaging events was the debris flow in the Faucon torrent in 2003 which affected six houses as well as the main road crossing the valley (R.D. 900) and led to its closure for several hours (Remaître, 2006; Remaître and Malet, 2010). Even though information on a number of events may exist, records indicating source areas are missing and impede the calibration of a statistical model. Likewise, in-depth information on environmental parameters, indispensible for the calibration of regional deterministic models, is missing and leads to the selection of an empirical model. The methodology applied in this study, consists of empirical rules for source identification and empirical relations for the modelling of the runout on a medium to regional scale. Runout refers in this article to the complete 2-D pathway of the debris flow from source to deposition area. An analysis aiming at a preliminary worst-case ${ }^{1}$ debris-flow susceptibility identification was carried out. In a further step the applicability of the methodology for scenario analyses was also investigated, estimating areas of high, medium and low susceptibility. Both analysis-types, worst-case and qualitative scenarios, were evaluated qualitatively on the basis of a set of recorded events.

\footnotetext{
${ }^{1}$ Worst-case scenario refers to a very low-frequency and rather high-magnitude event.
} 


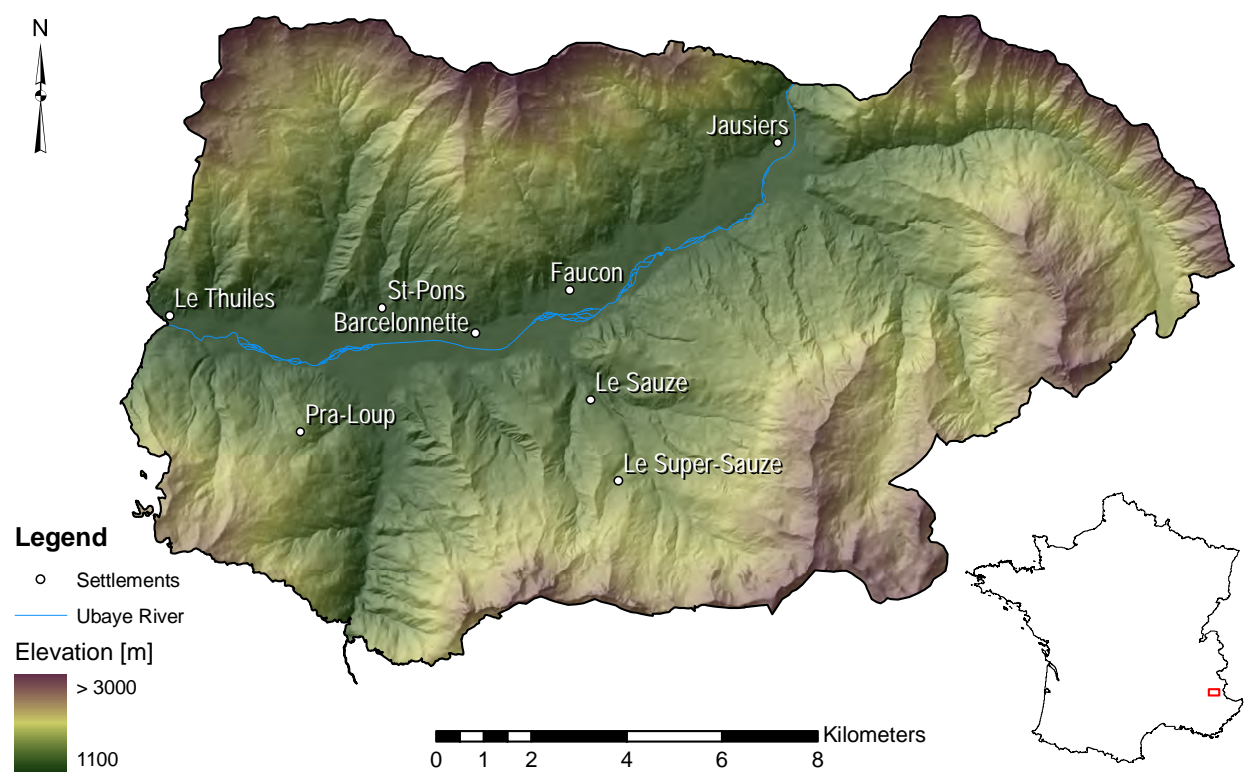

Fig. 1. Hillshade of the Barcelonnette Basin (Southern French Alps) with the location of the most important human settlements and the Ubaye River.

\section{The Barcelonnette Basin}

The Barcelonnette Basin is located in the dry intra-Alpine zone and extends from 1100 to $3000 \mathrm{~m}$ a.s.l. (Fig. 1). It is characterised by (1) a mountain climate with a marked inter-annual rainfall variability $(735 \pm 400 \mathrm{~mm}$ over the period 1928-2004) and 130days of freezing per year, (2) a continental influence with significant daily thermal amplitudes $\left(>20^{\circ}\right)$ and numerous freeze-thaw cycles and (3) a Mediterranean influence with summer rainstorms yielding more than $50 \mathrm{~mm} \mathrm{~h}^{-1}$ on occasion (Maquaire et al., 2003; Flageollet et al., 1999). Heavy spring rains on melting thick snow layers also lead to high discharges (Flageollet et al., 1999). Meso-climatic differences on a small scale emerge due to the east-west orientation of the valley (Remaître, 2006).

The valley is drained by the Ubaye River which is fed by several torrents on the north- and south-facing slopes. It constitutes a geological window, baring the autochthonous Callovo-Oxfordian black marls, also called 'Terres Noires', under the allochthonous Autapie and Parpaillon flysch (Maquaire et al., 2003). Local slopes are characterised by a specific morphology due to the geological setting:

(a) In the upper part (1900-3000 ma.s.1.), slopes are steeper than $45^{\circ}$ and consist of thrust sheets of cataclastic calcareous sandstones. These slopes are often covered by non-consolidated debris varying in thickness between 0.5 and $5 \mathrm{~m}$. Several debris tracks are affecting these slopes. (b) The gentle slopes $\left(10-30^{\circ}\right)$ of the lower part (11001900 m a.s.1.) consist of Callovo-Oxfordian black marls, mainly composed of fragile plates and flakes packed in a clayey matrix. Slopes are covered by various Quaternary deposits: thick talus slopes of poorly sorted debris, moraine deposits and landslide debris. The high erosion susceptibility of the black marls promotes badland formation.

This geological, structural and climatological setting gives rise to mass movements (Flageollet et al., 1999), active torrential streams and debris tracks (Remaître et al., 2005, 2008; Remaître and Malet, 2010). Moreover, the region suffered nearly complete deforestation during the 18th and 19th centuries, which increased the torrent activity. Reforestation and construction of check-dams was initiated in 1864 and since then, forest cover has been rising (Remaître and Malet, 2010). The collection of historical data in catalogues, newspapers, monographs, technical reports, bulletins and scientific papers for the period between 1850 and 2004 provides evidence of 561 torrential events. The type and quality of information collected, and the methodologies used to analyse the data are detailed in Flageollet et al. (1999) and Remaître (2006). The analysis indicates a dominance of flash floods with 461 recorded events while only 100 debris-flows (slope and gully) have been registered. The spatial distribution of historical debrisflows shows that they have occurred mainly in the torrents located on the south-facing slope of the Barcelonnette Basin. Indeed, about $75 \%$ of the debris-flow events were recorded in four torrents: Riou-Bourdoux, Sanières, Faucon and 
Bourget. This has to be ascribed (1) to the location of springs in the transition between the permeable, coarse material of the Autapie thrust sheet and the Callovo-Oxfordian black marls below, (2) to the higher slope angle and (3) to the thicker morainic coverage on the south-facing slopes which gives rise to a higher material availability.

Further possible sources for debris flows are the three big mudslides of La Valette, Super-Sauze and Poche which have developed in the black marls. Having already produced several mudflows and debris-flow events in recent years, they pose a serious menace due to their high sediment volumes and mobility (Malet et al., 2004).

\section{Method}

\subsection{The debris-flow modelling}

The debris-flow modelling was carried out in two steps: (1) the identification of potential source areas and (2) the calculation of the runout. According to Takahashi (1981) and Rickenmann and Zimmermann (1993) the critical factors for debris-flow occurrence are sediment availability, water input and slope gradient. While sediment availability and slope gradient refer to the general disposition, the water input from precipitation and snow melt acts as a triggering factor. To represent these factors by areawide available data the following inputs were chosen: the sediment availability is linked to the lithology since the debris production depends on the material characteristics and furthermore the slope shape influences the accumulation of material - the parameters lithology and planar curvature were included. The water input is strongly related to the upslope area in which precipitation and water from melting snow accumulate and so the parameter flow accumulation was implemented. The third factor, the slope gradient, is critical due to its influence on the shear strength of the soil and debris, respectively. Therefore, the parameter slope angle was integrated. Furthermore the land use/cover was considered since according to Ancey (2001) "[v]egetation reduces the initiation potential to a certain extent". Thus, the parameter land use/cover was incorporated. Each input parameter is entered as a raster into the modelling procedure. User-defined thresholds classify the pixels of the continuous data (e.g. slope, flow accumulation and planar curvature) as favourable for mobilisation (the pixels are marked included which indicates them as possible source) or inhibiting (the pixels are excluded from being a possible source) debris flow initiation. In the case of slope angle and upslope area a combined approach is applied as for example proposed in Rickenmann and Zimmermann (1993) or Heinimann et al. (1998): below a certain upslope area size threshold the slope angle is a function of the upslope area size and above the threshold the angle is constant (Fig. 2). Horton et al. (2008) propose two curves, the rare and the extreme fitting (Fig. 2). For upslope areas bigger than $2.5 \mathrm{~km}^{2}$ both curves

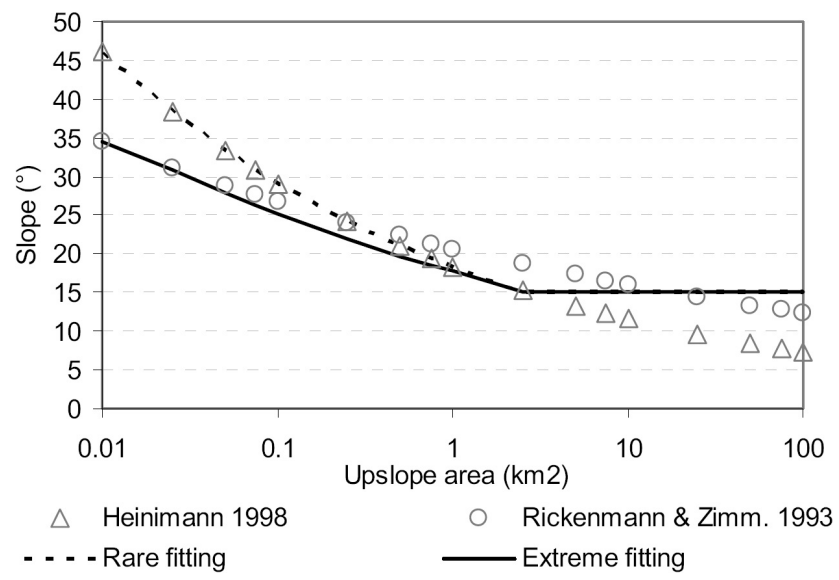

Fig. 2. Extreme and rare slope thresholds for debris-flow triggering with regard to the upslope area after Horton et al. (2008), considering Heinimann et al. (1998) and Rickenmann and Zimmermann (1993).

set the slope threshold at $15^{\circ}$ (Takahashi, 1981) while smaller catchments are only considered as possible sources if the slope angle lies above the threshold function. The two equations are the following (Horton et al., 2008):

Rare events

$\begin{cases}\tan \beta_{\lim }=0.32 \cdot S_{\mathrm{UA}}^{-0.2} & \text { if } \quad S_{\mathrm{UA}}<2.5 \mathrm{~km}^{2} \\ \tan \beta_{\mathrm{lim}}=0.26 & \text { if } \quad S_{\mathrm{UA}} \geq 2.5 \mathrm{~km}^{2}\end{cases}$

Extreme events

$\left\{\begin{array}{lll}\tan \beta_{\lim }=0.31 \cdot S_{\mathrm{UA}}^{-0.15} & \text { if } & S_{\mathrm{UA}}<2.5 \mathrm{~km}^{2} \\ \tan \beta_{\mathrm{lim}}=0.26 & \text { if } & S_{\mathrm{UA}} \geq 2.5 \mathrm{~km}^{2}\end{array}\right.$

with the slope gradient $\beta_{\text {lim }}$ and the surface of the upslope contributing area $S_{\mathrm{UA}}$. For the classified datasets land use/cover and lithology those classes prone to debris flows are designated as included as e.g. moranic deposits or excluded as possible source, such as built-up areas. Finally all classified spatial input parameters are combined and pixels being at least once determined as possible debrisflow source (included) and never excluded are assigned as sources.

In a second step the probabilitistic runout is calculated, starting from the previously determined sources and using two types of functions: flow direction and runout distance algorithms. It is a probabilistic propagation as it aims to incorporate every possible path with a notion of probability. Thus, it does not intend to process the spreading of a unique event, but to include all possible events. The flow direction algorithm defines the propagation of the flow from one cell to the surrounding neighbours starting with a source cell (Horton et al., 2008). A variety of algorithms is available: the D8 and D $\infty$ algorithm of O'Callaghan and Mark (1984) and Tarboton (1997), respectively, which are restricted to 
one flow direction following the steepest downward slope. The multiple flow direction method (Quinn et al., 1991) and its modification (Holmgren, 1994) which spread the flow on a percentage basis over several neighbouring downslope pixels are more realistic. The modified multiple flow direction method after Holmgren (1994) is expressed by the following formula:

$f_{i}=\frac{\left(\tan \beta_{i}\right)^{x}}{\sum_{j=1}^{8}\left(\tan \beta_{j}\right)^{x}}$ for $\tan \beta>0$

with $i, j=$ flow direction $(1 \ldots 8), f_{i}=$ flow proportion $(1 \ldots 0)$ in direction $i, \tan \beta_{i}=$ slope gradient between the central cell and cell in direction $i$ and $x=$ variable exponent. For $x=1$ the formula turns into the basic multiple flow direction method by Quinn et al. (1991) exhibiting a very wide spreading, while for higher $x$ values the flow converges more and more and becomes a single direction flow for $x \longrightarrow \infty$ (O'Callaghan and Mark, 1984). In addition to the influence of the slope on the flow direction, the effect of any directional change is considered, in other words the inertia of the flow. In the modeling context this parameter is called persistence which is a weight defined as a function of the change in angle from the last flow direction. Thus the final probabilities are the combination of the spreading and the persistence (Horton et al., 2008).

The distance reached by the flow is computed with simple energy-based calculations not considering source masses since they are mostly unknown in first medium-scale analyses. The kinetic energy $E_{\text {kin }}$ at the time step $i$ is obtained by the following formula:

$E_{\mathrm{kin}}^{i}=E_{\mathrm{kin}}^{i-1}+\Delta E_{\mathrm{pot}}^{i}-E_{\mathrm{loss}}^{i}$

with $\Delta E_{\text {pot }}^{i}=$ the change in potential energy and $E_{\text {loss }}^{i}=$ the constant loss. For the estimation of the energy loss, a constant friction loss angle referring to the angle of reach (Fahrböschung) concept (Heim, 1932; Corominas, 1996) is added. The angle of reach is defined as the angle between the horizontal and an imaginary line connecting source area and the end point of the flow along the flow path. This angle of reach is applied as a constant friction loss during the propagation from pixel to pixel. The flow stops as soon as the kinetic energy drops below zero. The procedure of runout calculation is performed for each source pixel and results in two products (output grids), the kinetic energy and the spatial probability. Where the flows originating from different sources overlap, either the maximum value or the sum of the spatial probabilities is computed. For the kinetic energy always the maximum value of overlapping flows is calculated.

Summarizing, this methodology enables a first assessment of the overall area possibly giving rise to debris-flows (source identification) and the area potentially affected by the debrisflow runout. Not single events but the sum of all possible incidences is estimated. This modelling approach was implemented in the Flow-R model which has been developed at the University of Lausanne (Horton et al., 2008) and is available on request at www.flow-r.ch.

\subsection{Data acquisition}

\subsubsection{Distributed data}

A digital elevation model (DEM) with a resolution of $10 \mathrm{~m}$ was calculated on basis of the digitised contour lines and breaklines of channels of the 1:10000 topographic maps from IGN (Institut Géographique National). Scanning and georeferencing of the maps have been carried out by Thiery et al. (2007) and the interpolation was realised with the software program SURFER using a kriging method and the semivariogram elaborated by Thiery (2006). The resulting DEM was smoothened by 9-nodes averaging, the sinks were filled and flow accumulations as well as planar curvature were derived. On basis of the aerial photographs of 2004 the land use was digitised and classified into dense coniferous forest, coniferous forest of average to low density, deciduous forest, natural grassland, arable land/permanent crops, pastures, bare rock, bare soil, urban areas, mining sites, water courses and marshes and water bodies (Bordonné, 2008). The information on the lithology was digitised from the geological map (1:50000) and converted into a raster file with $10-\mathrm{m}$ resolution as the DEM, constituting the following ten classes: marls, torrential alluvium, limestone, boulder fields, talus slopes, flysch, gypsum, lacustrine deposits, calcareous marls and moraines (Bordonné, 2008).

Although the resolution of the geological map is rather low, this information was included due to the importance within the modelling procedure. A possible option to cope with small-scale input is according to Bell and Glade (2004) the display of the final result in accordance to the scale of the least detailed input. We complied with this principle by preparing the resulting maps at a scale lower than 1:50000.

\subsubsection{Inventory data}

A first inventory comprises the envelopes (polygons) of the deposition of the debris-flow events observed in 1996, 2002 and 2003 at the Faucon, Sanières and Bourget torrents based on post-event field observations (Remaittre, 2006). The inventory is later on included in Fig. 6. A second debrisflow inventory using aerial photograph interpretation was compiled by Stummer (2009). By means of comparison of each two consecutive aerial photographs of the years 1956, 1974, 1982, 1995, 2000 and 2004, debris flows which had happened in each of the periods were visually identified and digitised. This collection comprises mostly small events on steep slopes while bigger events flowing principally in the torrents are in most cases not identifiable. Furthermore, neither the source nor the deposition area could be identified for all events, thus we extracted only the digitized linear flow 
paths (lines) to be used in this study. The inventory covers only a part of the study area, and the Abriès catchment, for example, was not mapped. A drawback of this method is that very active torrents producing debris flows in each time step can not be identified since no differences are visible between the consecutive photographs (the inventory is later on included in Fig. 4). A third inventory contains the number of events per torrent/catchment between 1850 and 2004, compiled from archive investigation by Sivan (2000) and Remaitre (2006). Geographically this information can only be linked to the respective torrent/whole catchment since no detailed information about source, runout and deposition is available. The three inventories were not merged into one overall inventory since they comprise very differing information (regarding type of information, resolution, shape etc.) but retained separately and used for distinct purposes as detailed in the following sections.

\subsection{Model parameter determination}

\subsubsection{Source identification}

For the first modelling step, the source identification, the three topographic parameters slope, flow accumulation and planar curvature were complemented by lithology and land use. Each parameter was implemented as 10-m raster into the model and the following criteria were applied for the classification of the single grid layers: the threshold for the size of the upslope area was considered in relation with the slope angle as explained in the model description and the extreme fitting (Fig. 2) was chosen since it allows, in contrast to the rare fitting, the identification of small and less steep sources, too, and matches the objective of worst-case scenario modelling well. The threshold for planar curvature was set to $-2 / 100 \mathrm{~m}^{-1}$ according to the experience of Horton et al. (2008) in the Canton de Vaud, Switzerland.

All geological units but the limestone were included as potential source areas. This includes torrential deposits, moraines, boulder fields, marls and calcareous marls, talus slopes, lacustrine deposits, gypsum and flysch. Concerning land use, dense coniferous forest, deciduous forest, natural grassland, arable land/permanent crops, pastures, urban areas and mining sites were excluded and coniferous forest (average to low density), marshes and water bodies, bare rock and bare soil were included.

Finally, all pixels being at least once included and never excluded as possible source were designated as susceptible to debris flow initiation.

\subsubsection{Runout}

\section{Worst-case scenario}

To define the runout distance for the worst-case scenario the literature was revised for minimum values of angles of reach in debris-flow inventories and already existing estimates of worst-case angles: Huggel et al. (2002) established a worst-case angle of reach for debris flows resulting from glacier lake outbursts. Reviewing a number of cases in the European Alps and in Canada, they fitted a curve to the angle of reach as function of the maximum discharge and assessed a threshold angle of $11^{\circ}$. Zimmermann et al. (1997) studied a set of debris flows especially in the Swiss Alps and found a minimum angle of reach of $\sim 11^{\circ}(20 \%)$ for coarse- and medium-grained and $\sim 7^{\circ}(12 \%)$ for fine-grained debris flows. Prochaska et al. (2008) identified, reviewing a large quantity of investigations, a minimum angle of reach of $6.5^{\circ}$. Bathurst et al. (1997) mention a rule of thumb applied in Japan using an angle of about $11^{\circ}(20 \%)$ according to T. Takahashi, personal communication, 1994. Rickenmann and Zimmermann (1993) mapped about 800 debris-flow events, triggered in the Swiss Alps during intense rainstorms in the summer of 1987 and identified a minimum angle of reach of nearly $11^{\circ}$. We chose the lowest angle found in the literature: $\sim 7^{\circ}$ and added the angle of $11^{\circ}$ since it was mentioned several times, including as result of a statistical analysis for the worst-case runout angle calculation (Huggel et al., 2002).

For the spreading of debris flows Holmgren (1994) proposes a range of $x$ between 4 and 6 in the Eq. (3) and Claessens et al. (2005) and Horton et al. (2008) chose $x=4$ for their debris-flow modelling (the lower the exponent the wider the spreading). However, since the objective is not to model a certain event realistically but to compute a worstcase scenario the widest spreading possible was applied choosing $x=1$. Thus, the spreading is not representing a single event but covers the extent of all possible events.

\section{Qualitative susceptibility scenarios}

Apart from worst-case-runout-modelling the capability of the methodology to assess certain hazard scenarios was investigated, based on the following assumptions: according to Corominas (1996, p. 270 and 260) "the relative mobility increases with the volume of the landslide" and "[t]he angle of reach is found to be a proper indicator of the relative mobility of landslides" (the term landslide is used by Corominas (1996) for a range of processes and among them the debris flows). Corominas and Moya (2008, p. 198) link the different magnitudes with frequency: "it has been observed that large landslides are able to travel for longer distances than smaller ones. Should small and large landslides be produced in the source area, most of them would reach points located close to the source but only a small percentage - the largest landslides - would reach points located far away. Consequently, the observed temporal frequency of the landslide events will decrease with the distance from the landslide source. Frequency is, therefore, a spatially distributed parameter". Thus it should be possible to define several magnitude- and frequencyscenarios, respectively, and to model them by means of 


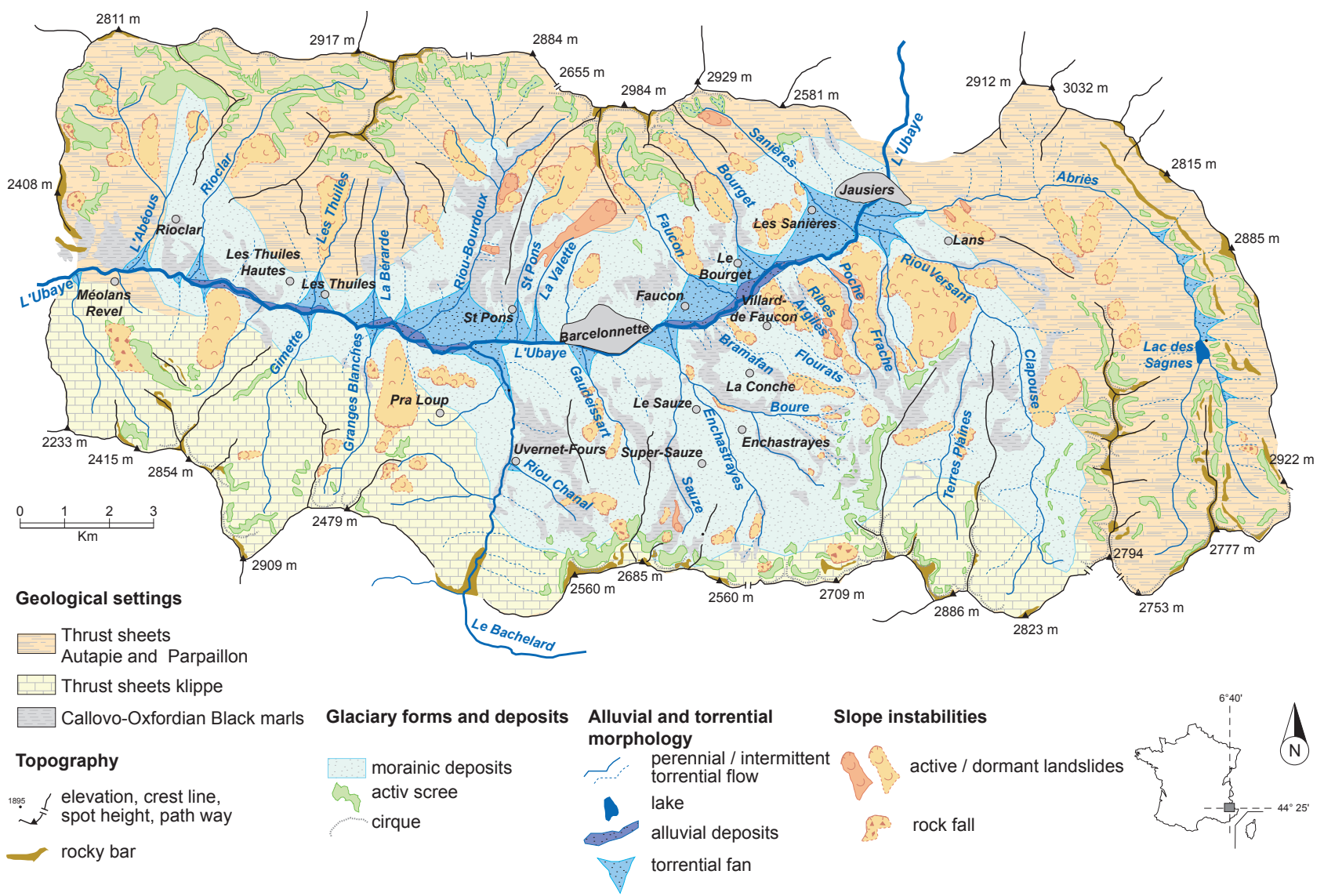

Fig. 3. Geomorphological map of the Barcelonnette Basin depicting the extent of the torrential fans, after Remaitre (2006).

different angles of reach. Smallwood et al. (1997) cite a classification of Morgan et al. (1991) into small $\left(<50 \mathrm{~m}^{3}\right)$, medium $\left(50-500 \mathrm{~m}^{3}\right)$, large $\left(500-5000 \mathrm{~m}^{3}\right)$ and very large $\left(>5000 \mathrm{~m}^{3}\right)$ debris flows with angles of reach of $13.5^{\circ}$, $13.5^{\circ}, 11^{\circ}$ and $8^{\circ}$.

Since in the Barcelonnette Basin information on the volume and the corresponding angle of reach is available only for one event no analyses on volume - angle of reach relationships and no computation of magnitude-frequency scenarios could be carried out. However, a high potential was seen in the two spatial inventories available: in the aerial photograph interpretation (Stummer, 2009) a number of small debris flows has been identified and the number per time interval between two photographs indicates a relatively high frequency of several events per year in the study area, forming the basis for the high frequency scenario. The second spatial inventory, compiled by Remaitre (2006), which consists of the debris-flow footprints of 1996, 2002 and 2003 on the fans of Sanières, Faucon or Bourget, indicates events of medium frequency which occur every few years and show a higher magnitude than the previous ones. These two constellations of high-frequency low-magnitude and medium-frequency medium-magnitude events were complemented by a third one for low-frequency high-magnitude on basis of the following assumption: the torrential fans (Fig. 3) are predominantly the result of debrisflow events, this means they were affected in the past and will possibly be affected in the future. Thus, the runout angle was iteratively adjusted and set as low as necessary to cover the length of the torrential fans (especially of those torrents described in the literature as very dangerous as e.g. the Riou Bourdoux) as far as the confluence with the Ubaye River.

Following the suggestion of Horton et al. (2008) to set the exponent in the spreading algorithm of Holmgren between 4 and 6 for debris flows, a value of 5 was chosen for all three scenarios. This is a less wide spreading than in the worst-case model (with an exponent of 1) for which an especially wide spreading was chosen. The fitting was done by modelling with several angles of reach and adjusting recalculations to adapt the model to the runout distance of the recorded events.

\subsection{Assessment of the model performance}

Beguería (2006) presents two main approaches for the validation of predictive models: confusion matrices for classified results and receiver-operating characteristics (ROC) for continuous results. With confusion matrices the modelling result is opposed to the recorded events resulting in four groups (Carranza and Castro, 2006): true positives (event 
observed and model identified the threat), true negatives (no event observed, no threat modelled), false positives (no event observed but model identified threat) and false negatives (event observed but no threat was modelled). The ROC curves oppose the false positive to the true positive rates by continuously changing the threshold used for the classification (Carrara et al., 2008). Due to the low availability of spatial information on past events only two measures were implemented: the sensitivity which is "the proportion of positive cases correctly predicted" and its opposite, the false negative rate which is "the proportion of false negatives in the total of positive observations" (Beguería, 2006, p. 321). The modelling results were furthermore evaluated in a qualitative way.

\subsubsection{Source identification}

The identified sources were visually compared with the aerial photograph inventory (Stummer, 2009) and the record of the debris flow of the Faucon catchment of 2003 (Remaitre, 2006), where the source area had been mapped in the field. Furthermore, the percentage of source pixels per catchment was compared with the percentage of events which had happened between 1850 and 2004 in several catchments. Based on the assumption that catchments exhibiting a higher extension of unstable area produce more debris flows over time, the percentage of modelled source area was compared to the percentage of recorded events per catchment. An attempt was made to use the assumed relation for the validation of the modelling results.

\subsubsection{Runout}

The runout model performance was assessed by means of a comparison of the potentially affected areas with the footprints of the past events. Since the modelling of the runout is based on two types of functions, the flow direction (or spreading) and runout distance algorithms, consequently the validation is also split into these two categories. This means that the longitudinal profile and the lateral characteristics of the flows are revised. For the worst-case scenario an enclosure of all past events into the modelled area is assumed and checked by an overlay of the area susceptible according to the model and the footprints of recorded debris flows.

The fitting of the susceptibility scenarios (high, middle and low frequency) was also assessed in a qualitative way comparing the modelling results with the spatial inventories of Stummer (2009); Remaitre (2006) and the longitudinal coverage of the torrential fan of the Riou-Bourdoux. For the event in the Faucon catchment in 2003 it was possible to calculate the angle of reach since in this case the full debrisflow path from the source to the endpoint is available. It was compared to the angle of reach adjusted for the medium frequency scenario.

\section{Resulting susceptibility assessment}

\subsection{Source area identification}

The model identified approximately $0.96 \mathrm{~km}^{2}$ of potentially unstable area from a whole of $199.66 \mathrm{~km}^{2}$. About $65 \%$ are located on the north-facing slopes including the Abriés catchment and $35 \%$ on the south-facing slopes (Fig. 4a). However, the highest percentage of potential sources (of over 45\%) was identified in the Abriés catchment. Leaving this catchment out of the calculation, $71 \%$ of the sources are located on the south-facing and only $29 \%$ on the north-facing slopes.

The ranking of the catchments according to the percentage of recorded events shows especially for the four most active torrents Riou-Bourdoux, Sanières, Faucon and Bourget a very good relation with the ranking on basis of the percentage of the area of modelled sources per catchment (diagram in Fig. 5). For the four other south-facing catchments possessing much lower percentages of recorded events as well as modelled sources no clear trend is visible. However, the order of magnitude of modelled and recorded percentages is similar. The south-facing catchments show in general very low numbers of recorded events and also the percentages of modelled sources are very low, except for the RiouVersant and especially the Abriès catchment. No clear trends are observable and the orders of magnitude differ as well, especially for the Riou-Versant and the Abriès catchment which exhibit much higher percentages of modelled sources than recorded events although both catchments could not be included completely into the analyses. For several catchments such as Enchastrayes, Boure, Sauze or La Tour no events were recorded but the model identified potential sources. In only one case, the Claveaux catchment, events were recorded but no susceptible areas were computed.

The threat posed by possible debris-flow formation on the mudslides could be identified as well. Three possible source pixels were identified on the lower part of the Poche mudslide, 21 especially in the upper part of the La Valette mudslide and 27 relatively equally distributed on the Super Sauze mudslide.

The comparison with the 2003 debris flow in the Faucon catchment shows a clear identification of the source area (Fig. 4b). The comparison with the starting points of the events mapped on the aerial photographs by Stummer (2009) showed almost no exact matches, however many slope segments, gullies and channels obviously prone to debris flows could be identified by the source modelling (Fig. 4a).

\subsection{Runout area modelling}

\subsubsection{Worst-case scenario}

The results of the two models with angles of reach of $7^{\circ}$ and $11^{\circ}$, respectively, are matching nearly completely for the slopes and the torrential fans. Minor differences are 


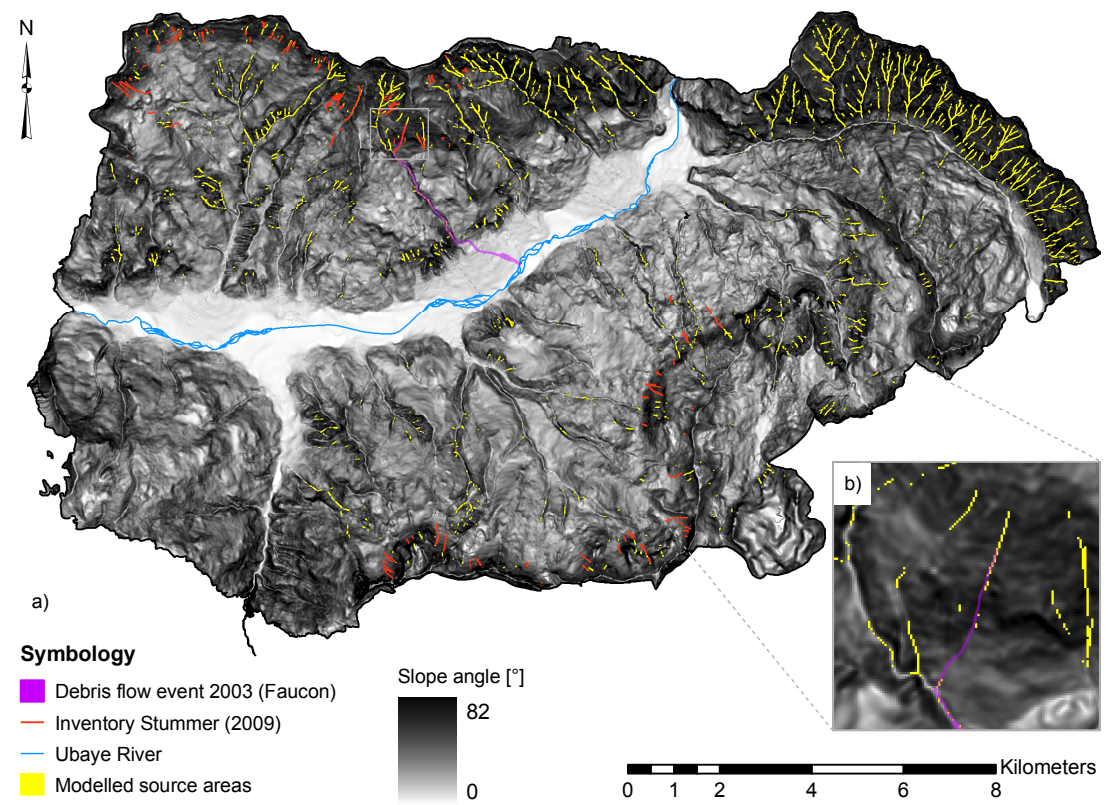

Fig. 4. Potential source areas identified by the model in comparison with the inventory by Stummer (2009) and the 2003 event observed in the Faucon catchment (Remaitre, 2006) (a) and an amplification of the upslope region of the Faucon catchment where the 2003 event had been triggered (b).

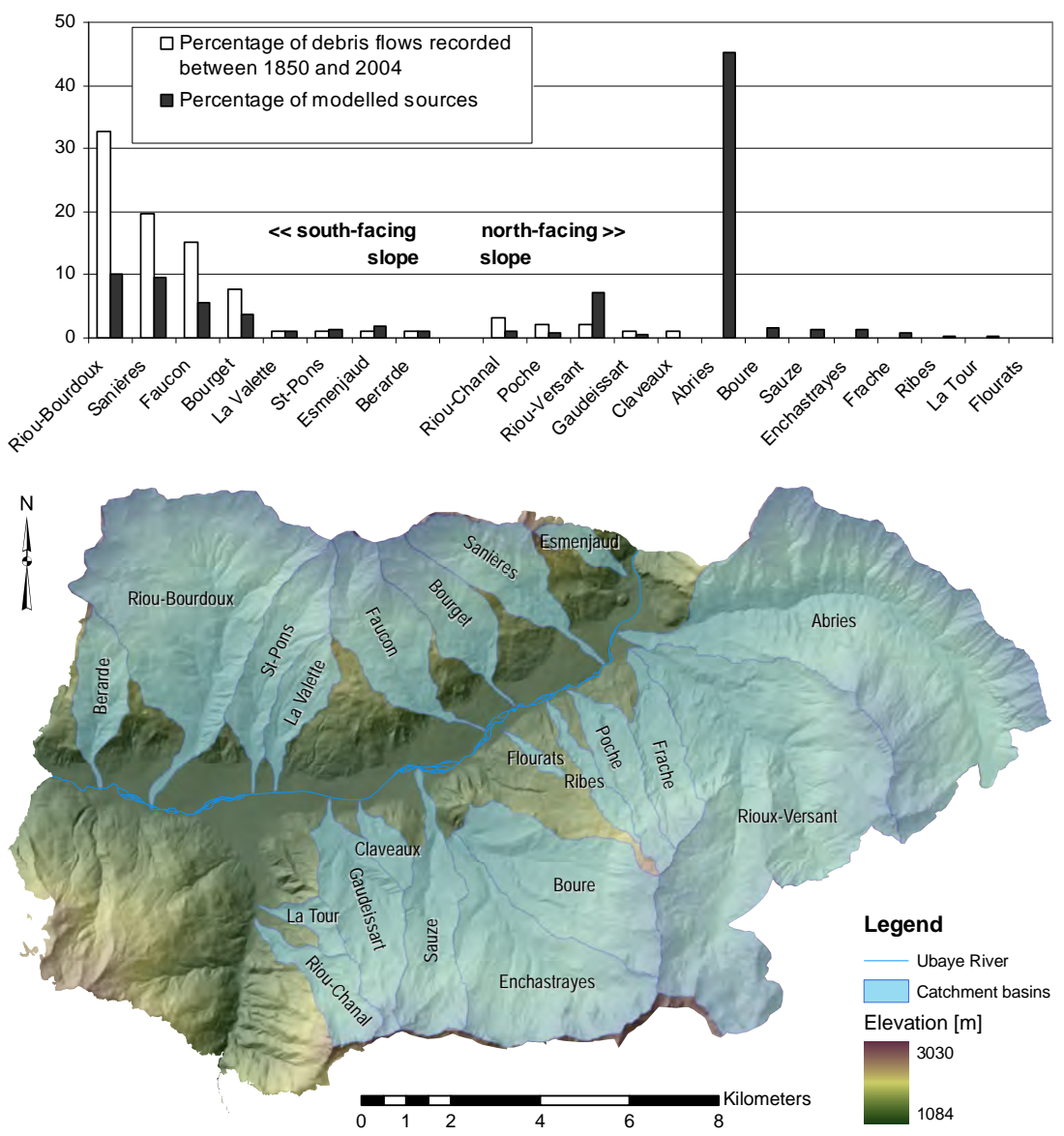

Fig. 5. Comparison of the source modelling result with the recorded events per catchment (diagram). The catchment locations are indicated in the map below the diagram. 


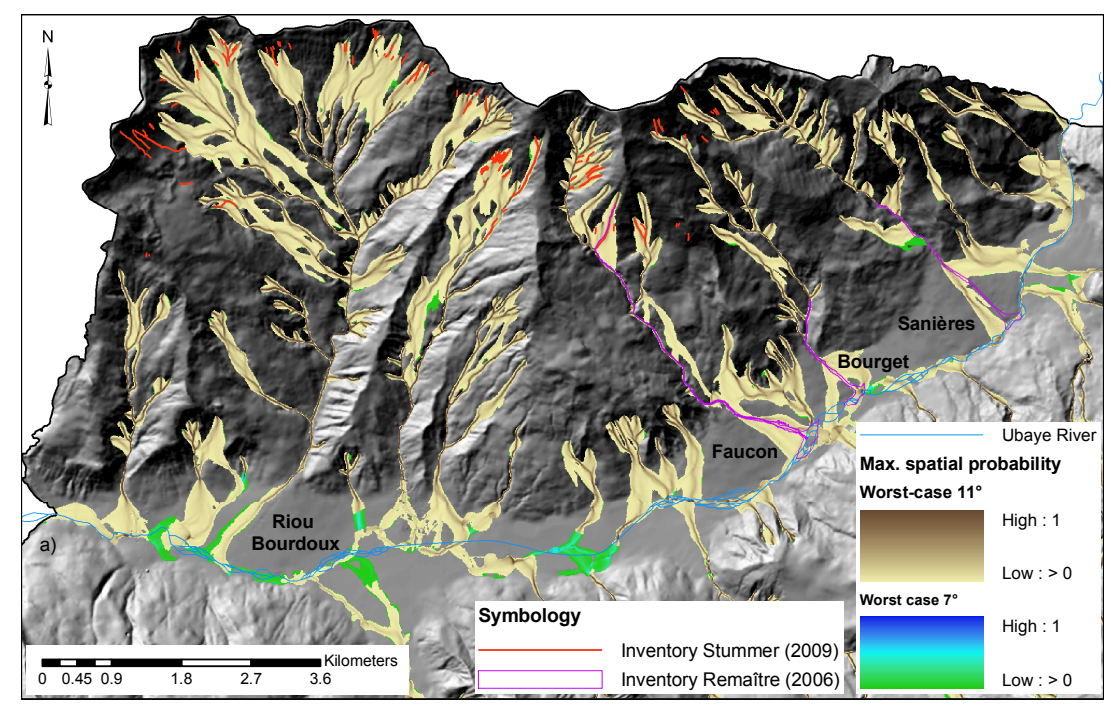

Fig. 6. Worst-case debris-flow scenarios showing the south-facing slope of the Barcelonnette Basin, with angles of reach of $7^{\circ}$ and $11^{\circ}$ (the $7^{\circ}$ scenario is underlying the $11^{\circ}$ scenario and identical with it for the area where it is invisible) in comparison with the debris-flow inventory according to Stummer (2009) and the inventory of Remaitre (2006) which consists of the envelopes of the observed events in 1996, 2002 and 2003.

observable only for the further runout in the flood plain of the Ubaye (Fig. 6). Longitudinally, the runouts are covering most of the torrential fans (Fig. 3), especially of the most active torrents Riou-Bourdoux, Faucon, Sanières and Bourget, and reach the confluence with the Ubaye.

The comparison of the modelling result with the footprints of the events of 1996, 2002 and 2003 shows a sensitivity of $77 \%$ which expresses the coincidence of the affected and modelled area. On the contrary the false negative rate amounts to $33 \%$ which refers to the area of recorded events but the modelling result does not indicate a threat. A closer look reveals, that the areas affected on the Faucon and Bourget torrential fan were modelled with only minor differences and the main course of the flow was identified (Fig. 8). In the case of the event in 2002 on the torrential fan of the Sanières torrent the model identified a strongly differing pathway, splitting shortly after having passed the apex of the fan into two flows while the event in 2002 had propagated straight ahead.

The comparison with the debris-flow courses mapped on the aerial photographs (Stummer, 2009) exhibits a 60\% coverage by the model. A high number of the mapped events is not or only partly covered since the respective source areas had not been identified but where the source areas were detected, the debris-flow courses identified on the photographs lie completely within the modelled susceptible area (see e.g. the Riou-Bourdoux catchment in Fig. 6).

\subsubsection{Qualitative susceptibility scenarios}

The adaptation of the model to the spatial inventories and using an assumption on extreme runout for the development of high (low), medium (medium) and low (high) frequency

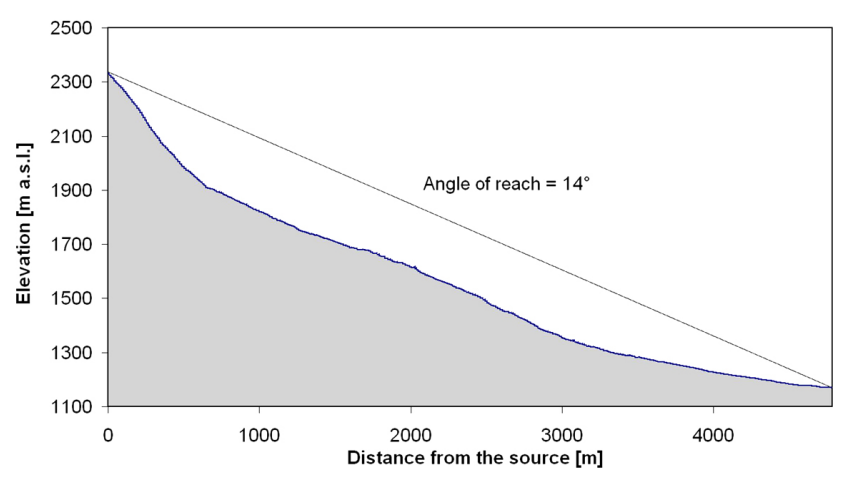

Fig. 7. Profile of the 2003 debris-flow in the Faucon torrent. A line for the identification of the angle of reach was positioned between the source area and the furthest point of the runout.

(magnitude) scenarios resulted in the following angles of reach: the adjustment to the inventory according to Stummer (2009) gave an angle of $30^{\circ}$ (Fig. 9). The modelling result represents events of low magnitude with a high frequency of several events per year distributed over the investigated area. The short flows are in most cases only flowing down the steep slopes and ending as soon as they get to the torrential channels. The torrential fans in the valley are not reached.

With an angle of reach of $14^{\circ}$ the maximum runout distance exhibited by the events in 1996, 2002 and 2003 of the torrents Faucon, Sanières and Bourget can be represented well. An investigation of the angle of reach of the debrisflow event in the Faucon torrent in 2003 also reveals an angle of reach of $14^{\circ}$ (Fig. 7), matching exactly the empirically (by model iteration) adjusted angle of reach for medium 


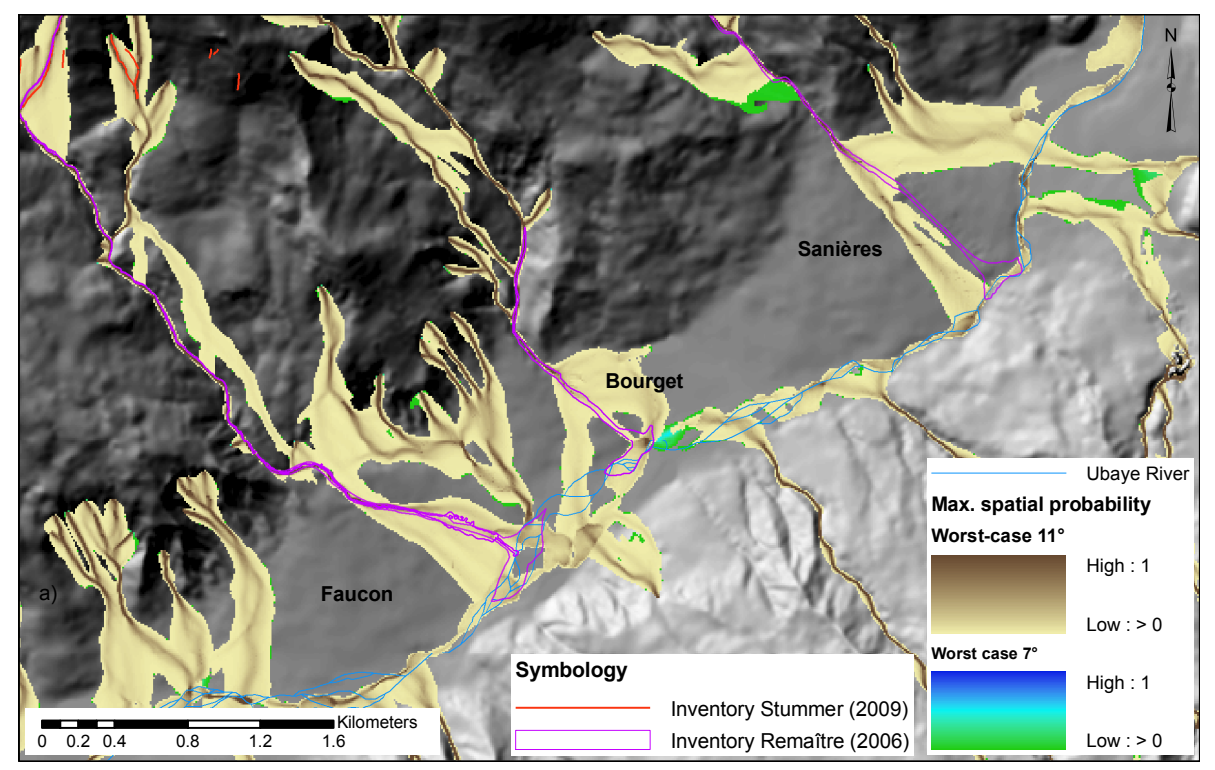

Fig. 8. Amplification of the three torrential fans showing the worst-case scenarios and the footprints of several observed events of the inventory of Remaître (2006).

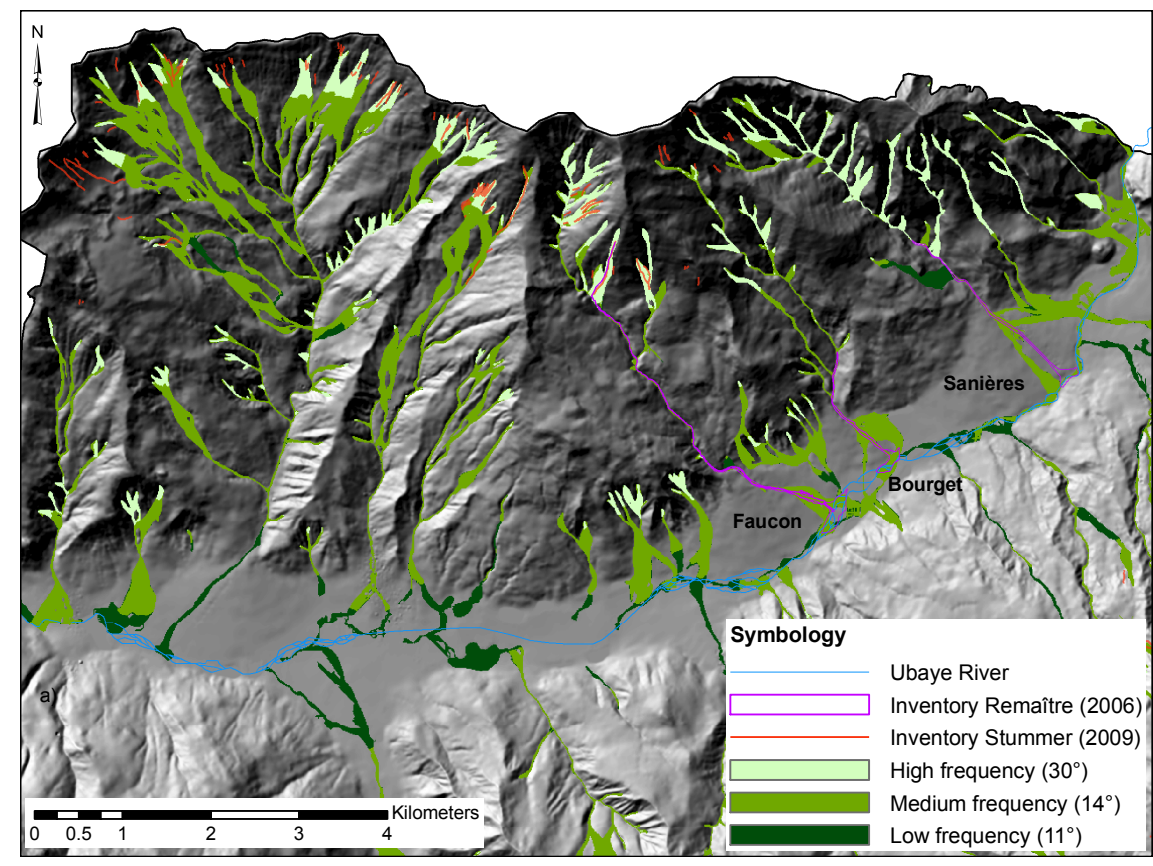

Fig. 9. Modelling results for the qualitative scenarios of high, medium and low frequency in comparison with the inventory after Stummer (2009) and the envelopes of events in 1996, 2002 and 2003 (Remaitre, 2006), showing the south-facing slopes.

frequency events. The comparison of the modelled spreading of the flow and the recorded events on the Faucon, Bourget and Sanières torrential fans exhibits a very similar result to the worst-case models. It shows the same pattern of a good identification of the flow pathways on the Faucon and Bourget fans but a strong deviation on the Sanières fan.
The higher value of the exponent in the spreading algorithm resulted in only marginally narrower spreading.

In contrast to the worst-case scenarios for the medium frequency scenario several other torrential fans are not reached by the modelled flows such as the Riou-Bourdoux and several north-facing torrents. 
The angle of reach identified to cover longitudinally the torrential fans of the valley is consistent with the $11^{\circ}$ worstcase scenario. As main indicator of the success of the modelling result on the torrential fan of the Riou-Bourdoux was observed, since this torrent was described in Sivan (2000) as one of the most active ones in the Barcelonnette Basin. Any higher angle than $11^{\circ}$ would not cover the whole length of the Riou-Bourdoux torrential fan till the Ubaye. For the other fans this angle exhibits good results as well and, as observed by the comparison of the $11^{\circ}$ with the $7^{\circ}$ worstcase model, virtually no differences could be identified for the runout on the slopes, in the channels and on the torrential fans.

\section{Discussion}

The source area identification could only be validated on the basis of a small number of evidences: the event of 2003, the aerial photograph interpretation inventory (Stummer, 2009) and a comparison of the percentage of recorded events with the percentage of modelled sources per catchment. A clear identification of the source of the 2003 event contrasts with a very low identification rate of the sources of smaller events of the aerial photograph interpretation inventory. However, the reasons for the difficulties in the identification are numerous, starting with the inventory itself which includes the source areas only in a few cases while for most events only segments of debris-flow tracks could be determined and mapped. Furthermore most of the events were obviously very small, having occurred in small gullies and concavities which are very difficult to identify with a $10-\mathrm{m}$ resolution DEM. The DEM creation on the basis of a topographic map with limited detail as well as the interpolation and smoothing led probably to further generalisation and loss of small scale forms. And finally, the high altitudinal differences in the area posed a challenge for the orthorectification of the aerial photographs resulting in small mismatches between the photographs and further spatial information. However, the very small sources are presumably not the ones releasing the very dangerous events and the larger channels and torrents to which they contribute are indentified in any case. Thus, the nonrecognition of these sources is most probably of minor effect on the runout on the torrential fans.

The assumption of a relation between the percentage of modelled source area and the percentage of recorded events seems at first sight viable and offers a possibility for qualitative validation. The two percentages indicate a good identification of the most important torrents on the south-facing slope Riou-Bourdoux, Faucon, Bourget and Sanières as well as a the same ranking of the four torrents (Fig. 5). Though the ranking is matching well the values are not directly comparable This fact is attributed to the high percentage of more than $45^{\circ}$ slopes of the modelled sources identified in the Abriès catchment while very few events were recorded. This leads to a distortion of the percentages of modelled sources for other catchments and especially in comparison with the percentages of recorded events. The explanation for the wide difference in the percentages of the Abriès catchment lies in its specific setting: the Abriès itself cannot be considered a torrent since it exhibits an only moderate slope of about $6.5^{\circ}$ (Remaître, 2006). However, a large number of small very steep torrents and gullies, tributaries to the main flow, were identified as very active by the model. Nevertheless, they are most probably not producing effects which would reach the confluence with the Ubaye and since the catchment is nearly unpopulated and no road is passing under the most active slopes, these comparatively small events were not recorded. A field check confirmed, that these small torrents are indeed very active, not only concerning debris flows but also rockfalls. For a number of catchments such as the Boure, Sauze or Riou de Ribes, only possibly unstable areas, but no events were recorded. Considering the minor morainic cover of the north-facing slopes already mentioned, the nonrecording of events is not necessarily a non-existence of past or future events but might indicate a lower frequency due to lower material availability. In conclusion the dependence of the comparability of the two percentages on the recording activity becomes obvious. However, taking this aspect into account the comparison served for discussion and validation purposes very well.

Between the two worst-case scenario models with angles of reach of $7^{\circ}$ and $11^{\circ}$ only minor differences were observed for the runout in the river bed of the Ubaye. This indicates, that an assumed worst-case angle of reach of $11^{\circ}$ would be sufficient to identify the areas threatened by debris flows in the Barcelonnette Basin. The possible further runout in the wide river bed is of less interest since the area is not used and a possible damming of the Ubaye River does not have to be expected due to the width of the bed. In general, the runout distance of former debris flows was captured very well in the worst-case scenario. However, despite its designation as worst-case scenario, it does not completely contain the area affected by the recorded past events. Especially on the torrential fan of the Sanières torrent the differences are very high since the model identified a diverging course of the flow and did not cover the actual event of 2002. The reason lies most probably in the quality of the DEM. Especially in relatively flat areas the spreading of the flow reacts very sensitively to elevation differences and thus to errors in the digital elevation model. DEMs built on digitised elevation lines which exhibit further runout distances for flatter areas are rather prone to generalisations of the actual topography as well as to errors. In contrast to the strong reaction of the spreading to errors, the runout distance seems to be much less sensitive. However to prove these hypotheses further investigation has to be carried out. The resulting errors are especially problematic for the worstcase modelling. Understanding this term literally would 
assure the safety of the complete area outside the identified regions. However, the interpretation of such modelling results can only be done being aware of the assumptions inherent in the model, its strong dependence on the quality of the DEM and the accuracy and scale of the input data.

The qualitative scenarios computed on basis of the empirically determined angles of reach match rather well with the inventories and the assumption of full longitudinal coverage of the largest torrential fans. Especially the fact that the angle of reach calculated for the 2003 event in the Faucon catchment matches exactly with the empirically adjusted angle. The match of the angle of reach of high magnitude events and the worst-case calibration indicate a good adjustment of the scenarios. However, the data basis on which the scenarios are defined and modelled is very small and the estimation of the frequencies and magnitudes of the three classes would have to be confirmed. The results have to be interpreted being aware of these facts. Against this background, the results indicate a ranking of susceptibility. Priorities for more detailed studies can be determined by this approach.

\section{Conclusions}

The aim of a medium-scale debris-flow susceptibility analysis as a first overview for the Barcelonnette Basin with limited spatial information on past events was fulfilled. The source areas as well as the worst-case runout modelling resulted in reasonable outcomes without sitespecific information linked to past events but by adoption of empirical relations and parametrisation developed in other regions. The comparison of the percentage of modelled sources with the percentage of recorded events per catchment proved very helpful, not only for the validation of the source modelling results but also for shedding light on the model, inventory and catchment characteristics. The development of scenarios needs more input and particularly estimations of the return periods of the events. However, detailed inventories containing information on angles of reach and volumes are not necessarily needed. With the model used in this study, a direct calibration of the scenarios on the basis of mapped deposition areas and frequency estimates is possible. The quality of the DEM was identified as a critical factor in the modelling process. Especially DEMs interpolated on the basis of contour lines exhibit a variety of errors and generalisations which have an important impact on the reliability of the modelled susceptibility. However, the application of the results lies in the identification of the most threatened areas and not in the determination of threatened areas for final decision making. E.g. effects such as volume-specific friction, scouring and increase of the volume during the movement cannot be taken into account but play an important role. The angle identified as angle of reach subsumes but does not describe the individual effects. Due to these strong generalisations, not even for the worst-case scenario can a guarantee be given that future events will lie entirely within the identified limits. The interpretation of the resulting maps is only possible with the knowledge of the model assumptions and the accuracy and scale of the input data. For future better adjustment of the model to unknown areas with low data availability it would be of great interest to fit the model to various settings and compare the parameterisation in relation to the environmental conditions. Information on the parameter ranges and the resulting differences, especially in regions with detailed information on angles of reach and volumes of past events, would provide support for the calibration of the model to unknown zones.

Acknowledgements. The authors are grateful to the European Commission for funding the Marie Curie Research Training Network Mountain Risks (http://mountain-risks.eu, contract MCRTN03598) within which the study could be carried out. Furthermore, the authors want to express their gratitude to an anonymous native speaker as well as to R. Genevois, J. Hübl and three unknown reviewers for suggestions and comments which helped to improve the quality of the article.

Edited by: J. Huebl

Reviewed by: R. Genevois and three other anonymous referees

\section{References}

Aleotti, P. and Chowdhury, R.: Landslide hazard assessment: summary review and new perspectives, B. Eng. Geol. Environ., 85, 21-44, 1999.

Ancey, C.: Geomorphological fluid mechanics, chap. Debris flow related phenomena, Springer Verlag, Berlin, Germany, 528-547, 2001.

Bathurst, J., Burton, A., and Ward, T.: Debris flow run-out and landslide sediment delivery model tests, J. Hydraul. Eng.-ASCE, 123, 410-419, 1997.

Beguería, S.: Validation and evaluation of predictive models in hazard assessment and risk management, Nat. Hazards, 37, 315329, 2006.

Bell, R. and Glade, T.: Quantitative risk analysis for landslides - Examples from Bíldudalur, NW-Iceland, Nat. Hazards Earth Syst. Sci., 4, 117-131, doi:10.5194/nhess-4-117-2004, 2004.

Benda, L. and Cundy, T.: Predicting deposition of debris flows in mountain channels, Can. Geotech. J., 27, 409-417, 1990.

Blahut, J., van Westen, C., and Sterlacchini, S.: Analysis of landslide inventories for accurate prediction of debris-flow source areas, Geomorphology, Geomorphology, 119(1-2), 3651, doi:10.1016/j.geomorph.2010.02.017, 2010.

Bordonné, M.: Cartographie de laves torrentielles dans le bassin de Barcelonnette, Master's thesis, Université Louis Pasteur, Strasbourg, 2008 (in French).

Carranza, E. and Castro, O.: Predicting lahar-inundation zones: case study in West Mount Pinatubo, Philippines, Nat. Hazards, 37, 331-372, 2006. 
Carrara, A., Crosta, G., and Frattini, P.: Comparing models of debris-flow susceptibility in the alpine environment, Geomorphology, 94, 353-378, 2008.

Chau, K. T. and Lo, K. H.: Hazard assessment of debris flows for Leung King Estate of Hong Kong by incorporating GIS with numericalsimulations, Nat. Hazards Earth Syst. Sci., 4, 103-116, doi:10.5194/nhess-4-103-2004, 2004.

Claessens, L., Heuvelink, G., Schoorl, J., and Veldkamp, A.: DEM resolution effects on shallow landslide hazard and soil redistribution modelling, Earth Surf. Proc. Land., 30, 461-477, 2005.

Corominas, J.: The angle of reach as a mobility index for small and large landslides, Can. Geotech. J., 33, 260-271, 1996.

Corominas, J. and Moya, J.: A review of assessing landslide frequency for hazard zoning purposes, Eng. Geol., 102, 193-213, 2008.

Delmonaco, G., Leoni, G., Margottini, C., Puglisi, C., and Spizzichino, D.: Large scale debris-flow hazard assessment: a geotechnical approach and GIS modelling, Nat. Hazards Earth Syst. Sci., 3, 443-455, doi:10.5194/nhess-3-443-2003, 2003.

Flageollet, J.-C., Maquaire, O., Martin, B., and Weber, D.: Landslides and climatic conditions in the Barcelonnette and Vars basins (Southern French Alps, France), Geomorphology, 30, 6578, 1999.

Glade, T.: Linking debris-flow hazard assessment with geomorphology, Geomorphology, 66, 189-213, 2005.

Guinau, M., Vilajosana, I., and Vilaplana, J. M.: GIS-based debris flow source and runout susceptibility assessment from DEM data - a case study in NW Nicaragua, Nat. Hazards Earth Syst. Sci., 7, 703-716, doi:10.5194/nhess-7-703-2007, 2007.

Heim, A.: Bergsturz und Menschenleben, Beiblatt zur Vierteljahresschrift der Naturforschenden Gesellschaft in Zürich, 1932.

Heinimann, H., Hollenstein, K., Kienholz, H., Krummenacher, B., and Mani, P.: Methoden zur Analyse und Bewertung von Naturgefahren, Umwelt-Materialien Nr. 85, Bundesamt für Umwelt, Wald und Landschaft (BUWAL), Bern, Switzerland, 1998 (in German).

Hofmeister, R. and Miller, D.: Debris-flow hazards mitigation: mechanics, prediction, and assessment, chap. GIS-based modeling of debris-flow initiation, transport and deposition zones for regional hazard assessments in western Oregon, USA, Millpress, Rotterdam, Netherlands, 1141-1149, 2003.

Hofmeister, R., Miller, D., Mills, K., Hinkle, J., and Beier, A.: Hazard map of potential rapidly moving landslides in Western Oregon, Interpretive Map Series IMS-22, Oregon Department of Geology and Mineral Industries, 2002.

Holmgren, P.: Multiple flow direction algorithms for runoff modelling in grid based elevation models: an empirical evaluation, Hydrol. Process., 8, 327-334, 1994.

Horton, P., Jaboyedoff, M., and Bardou, E.: Debris flow susceptibility mapping at a regional scale, in: 4th Canadian Conference on Geohazards, Université Laval, Québec, Canada, 2008.

Huggel, C., Kääb, A., Haeberli, W., Teysseire, P., and Paul, F.: Remote sensing based assessment of hazards from glacier lake outbursts: a case study in the Swiss Alps, Can. Geotech. J., 39, 316-330, 2002.
Hürlimann, M., Rickenmann, D., Medina, V., and Bateman, A.: Evaluation of approaches to calculate debris-flow parameters for hazard assessment, Eng. Geol., 102, 152-163, 2008.

Iverson, R. and Denlinger, R.: Mechanics of debris flows and debris-laden flash floods, in: Proceedings of the Seventh Federal Interagency Sedimentation Conference, 2001.

Iverson, R., Schilling, S., and Vallance, J.: Objective deliniation of lahar-inundation hazard zones, GSA Bulletin, 8, 972-984, 1998.

Malet, J.-P., Maquaire, O., Locat, J., and Remaître, A.: Assessing debris flow hazard associated with slow moving landslides: methodology and numerical analyses, Landslides, 1, 83-90, 2004.

Maquaire, O., Malet, J.-P., Ramaître, A., Locat, J., Klotz, S., and Guillon, J.: Instability conditions of marly hillslopes: towards landsliding or gullying? The case of the Barcelonnette Basin, South East France, Eng. Geol., 70, 109-130, 2003.

Melelli, L. and Taramelli, A.: An example of debris-flows hazard modeling using GIS, Nat. Hazards Earth Syst. Sci., 4, 347-358, doi:10.5194/nhess-4-347-2004, 2004.

O'Callaghan, J. and Mark, D.: The extraction of drainage networks from digital elevation data, Comput. Vision Graph., 28, 328-344, 1984.

Prochaska, A., Santi, P., Higgins, J., and Cannon, S.: Debris-flow runout predictions based on the average channel slope (ACS), Eng. Geol., 98, 29-40, 2008.

Quinn, P., Beven, K., Chevallier, P., and Planchon, O.: The prediction of hillslope flow paths for distributed hydrological modelling using digital terrain models, Hydrol. Process., 5, 9579, 1991.

Remaître, A.: Morphologie et dynamique des laves torrentielles: applications aux torrents des Terres Noires du bassin de Barcelonnette (Alpes du Sud), Ph.D. thesis, Université de Caen/Basse-Normandie, 2006 (in French).

Remaître, A. and Malet, J.-P.: The effectiveness of torrent check dams to control channel instability: example of debris flow events in clay shale, in: Check Dams, Morphological Adjustments and Erosion Control in Torrential Streams, edited by: Garcia, C. C. and Lenzi, M. A., Nova Science Publishers, 211-237, 2010.

Remaître, A., Malet, J.-P., Maquaire, O., C., A., and Locat, J.: Mobility of debris-flows in clays-shale basins. Part II: Flow behaviour, runout modelling and torrential hazard assessment, Earth Surf. Proc. Land., 30, 479-488, 2005.

Remaître, A., van Asch, Th. W. J., Malet, J.-P., and Maquaire, O.: Influence of check dams on debris-flow run-out intensity, Nat. Hazards Earth Syst. Sci., 8, 1403-1416, doi:10.5194/nhess-81403-2008, 2008.

Rickenmann, D.: Empirical relationships for debris flows, Nat. Hazards, 19, 47-77, 1999.

Rickenmann, D. and Zimmermann, M.: The 1987 debris flow in Switzerland: documentation and analysis, Geomorphology, 8, 175-189, 1993.

Scheidl, C. and Rickenmann, D.: Empirical prediction of debrisflow mobility and deposition on fans, Earth Surf. Proc. Land., 35, 157-173, 2010.

Sivan, O.: Torrents de l'Ubaye, Sabenca, Association de la Valeia, Barcelonnette, France, 2000 (in French). 
Smallwood, A., Morley, R., Hardingham, A., Ditchfield, C., and Castleman, J.: Engineering Geology and the Environment, chap. Quantitative risk assessment of landslides: case histories from Hong Kong, Balkema, Rotterdam, Netherlands, 1055-1060, 1997.

Stummer, R.: Räumliche und zeitliche Variabilität von Murereignissen, Master's thesis, University of Vienna, Austria, 2009 (in German).

Takahashi, T.: Estimation of potential debris flows and their hazardous zones; soft countermeasures for a disaster, Journal of Natural of Disaster Science, 3, 57-89, 1981.

Tarboton, D. G.: A new method for fhe determination of flow directions and upslope areas in grid digital elevation models, Water Resour. Res., 33, 309-319, 1997.
Thiery, Y.: Susceptibilité du bassin de Barcelonnette (Alpes du sud, France) aux "mouvements de versant": cartographie morphodynamique, analyse spatiale et modélisation probabiliste, Ph.D. thesis, Université de Caen/Basse-Normandie, 2006 (in French).

Thiery, Y., Malet, J.-P., Sterlacchini, S., Puissant, A., and Maquaire, O.: Landslide susceptibility assessment by bivariate methods at large scales: Application to a complex mountainous environment, Geomorphology, 92, 38-59, 2007.

van Westen, C., van Asch, T., and Soeters, R.: Landslide hazard and risk zonation - why is it still so difficult, B. Eng. Geol. Environ., 65, 167-184, 2006.

Zimmermann, M., Mani, P., and Gamma, P.: Murganggefahr und Klimaänderung - ein GIS-basierter Ansatz, vdf Hochschulverlag AG, ETH Zürich, 1997 (in German). 